\title{
Review Article \\ Effects of Antioxidant Supplements on the Survival and Differentiation of Stem Cells
}

\author{
Sara Shaban, ${ }^{1}$ Mostafa Wanees Ahmed El-Husseny, ${ }^{1,2}$ Abdelrahman Ibrahim Abushouk, ${ }^{2,3,4}$ \\ Amr Muhammad Abdo Salem, ${ }^{2,3}$ Mediana Mamdouh, ${ }^{1}$ and Mohamed M. Abdel-Daim ${ }^{5,6}$ \\ ${ }^{1}$ Faculty of Medicine, Fayoum University, Cairo, Egypt \\ ${ }^{2}$ NovaMed Medical Research Association, Cairo, Egypt \\ ${ }^{3}$ Faculty of Medicine, Ain Shams University, Cairo, Egypt \\ ${ }^{4}$ Medical Research Group of Egypt, Cairo, Egypt \\ ${ }^{5}$ Pharmacology Department, Faculty of Veterinary Medicine, Suez Canal University, Ismailia 41522, Egypt \\ ${ }^{6}$ Department of Ophthalmology and Micro-Technology, Yokohama City University, Yokohama, Japan \\ Correspondence should be addressed to Mohamed M. Abdel-Daim; abdeldaim.m@vet.suez.edu.eg
}

Received 25 February 2017; Accepted 31 May 2017; Published 9 July 2017

Academic Editor: Andreas Daiber

Copyright (C) 2017 Sara Shaban et al. This is an open access article distributed under the Creative Commons Attribution License, which permits unrestricted use, distribution, and reproduction in any medium, provided the original work is properly cited.

\begin{abstract}
Although physiological levels of reactive oxygen species (ROS) are required to maintain the self-renewal capacity of stem cells, elevated ROS levels can induce chromosomal aberrations, mitochondrial DNA damage, and defective stem cell differentiation. Over the past decade, several studies have shown that antioxidants can not only mitigate oxidative stress and improve stem cell survival but also affect the potency and differentiation of these cells. Further beneficial effects of antioxidants include increasing genomic stability, improving the adhesion of stem cells to culture media, and enabling researchers to manipulate stem cell proliferation by using different doses of antioxidants. These findings can have several clinical implications, such as improving neurogenesis in patients with stroke and neurodegenerative diseases, as well as improving the regeneration of infarcted myocardial tissue and the banking of spermatogonial stem cells. This article reviews the cellular and molecular effects of antioxidant supplementation to cultured or transplanted stem cells and draws up recommendations for further research in this area.
\end{abstract}

\section{Introduction}

Stem cells are undifferentiated cells, characterized by selfrenewal and the ability to differentiate into several cell types (potency) [1]. They can be totipotent (differentiating into embryonic and extraembryonic cell types), pluripotent (differentiating into cells of the three germ layers), or multipotent (differentiating into cells of a closely related family) [2]. Stem cell research runs with an incredible speed and its applications are under investigation in different medical fields $[3,4]$. There are two main types of stem cells: embryonic stem cells (ESCs) (present in the inner cell mass of the blastocyst) and adult stem cells (present in different mature tissues to replace dead cells) $[5,6]$.
Induced pluripotent stem cells (iPSCs) are adult cells, genetically reprogrammed to express genes and factors, required for maintaining the properties of ESCs. However, the reprogramming process itself results in oxidative stress by generating high levels of reactive oxygen species (ROS) $[7,8]$, which cause damage to DNA, RNA, and cell proteins and may induce apoptosis [9-11]. However, ROS are required in physiological levels to maintain the self-renewal capacity of stem cells and to fight invading microbes [11-14].

Antioxidants are biochemical supplements that protect cellular constituents from oxidative stress by neutralizing free radicals and terminating the oxidative reaction chain in the mitochondrial membrane [15]. They can be classified into enzymatic and nonenzymatic, endogenous and 
exogenous [16], and water-soluble (reacting with oxidants in the cytosol or plasma) and lipid-soluble antioxidants (preventing lipid peroxidation of cell membranes) [17].

Over the past decade, several studies have shown that antioxidants can not only mitigate oxidative stress and improve stem cell survival but also affect the potency and differentiation of these cells. In our article, we reviewed the results of preclinical studies that investigated the effects of antioxidants on cultured or transplanted stem cells in an attempt to draw up recommendations for further research in this area.

\section{Induced Pluripotent Stem Cells (iPSCs)}

As highlighted earlier, the reprogramming of iPSCs is associated with generation of high ROS levels. Several reports showed that, in comparison to somatic precursor cells, iPSCs exhibit the following criteria: (1) marked protection against nuclear and mitochondrial DNA (mtDNA) damage and (2) significantly lower levels of ROS due to upregulation of intrinsic antioxidant enzymes [18, 19]. Dannenmann et al. found a 10-fold decrease in ROS level and a fourfold increase of glutathione (GSH) and glutathione reductase (GR) levels in iPSCs, compared to fibroblasts [18]. In another study by the same authors, they showed that several glutathione Stransferases (GSTs), which act as antioxidant and detoxifying enzymes, were upregulated in iPSCs, compared to their somatic precursor cells [19].

$\mathrm{Ji}$ and colleagues reported that mitigation of oxidative stress during cellular reprogramming by antioxidant supplementation protects the genome of reprogramming cells against DNA damage and leads to iPSCs with fewer genomic aberrations [20]. In the same vein, Luo and colleagues [21] found that iPSCs grew well and "stemness" was preserved for up to two months after the addition of a lowdose antioxidant supplement. Moreover, using comparative genomic hybridization (CGH) analysis, they showed that antioxidant supplementation lowered the levels of genetic aberrations in cultured iPSCs [21].

Hämäläinen and colleagues showed that the reprogramming and self-renewal abilities of iPSCs were diminished after subtle increases in ROS levels, originating from mtDNA mutagenesis. However, the addition of two different antioxidants [N-acetyl-L-cysteine (NAC) and mitochondriatargeted ubiquinone (MitoQ)] efficiently rescued these abilities in mutator iPSCs [22]. N-acetyl-L-cysteine raises cellular GSH pool and promotes the processing of $\mathrm{H}_{2} \mathrm{O}_{2}$ in the cytosol [23], whereas MitoQ acts upstream to prevent superoxide production within the mitochondria before $\mathrm{H}_{2} \mathrm{O}_{2}$ generation [24]. Of note, Hämäläinen et al. highlighted that the therapeutic window of MitoQ for iPSCs is narrow, while high concentrations of NAC were not associated with toxic effects on iPSCs [22].

Interestingly, other reports showed no effect of antioxidant supplementation on the expression of 53BP1 and ATM proteins (two molecules involved in DNA repair pathways) [25-27]. Recently, it has been found that high-dose antioxidants downregulates DNA repair-related kinases, which conversely results in genomic instability of
iPSCs [21]. Therefore, adjusting the dose of supplementary antioxidants is critical.

\section{Bone Marrow-Derived Mesenchymal (BMSCs) and Hematopoietic Stem Cells (HSCs)}

Several studies showed that the ex vivo expansion of ESCs and mesenchymal stem cells (MSCs) [28-31] and the in vitro expansion of HSCs [32] may cause genomic instability. Through a serial transplantation assay, Jang and colleagues showed that elevated ROS levels reduce the self-renewal ability of HSCs [33]. Therefore, decreasing $\mathrm{O}_{2}$ concentrations to physiological levels or adding proper dosages of antioxidants can reduce in vitro, culturestimulated aneuploidy, providing potential methods to limit genomic alterations when expanding HSCs in vitro $[32,34,35]$. Hamid et al. conducted an in vitro study to evaluate the antioxidant effects of Hibiscus sabdariffa L. (roselle) on bone marrow-derived HSCs. They showed that roselle supplementation increased superoxide dismutase (SOD) expression (at 125, 500, and $1000 \mathrm{ng} / \mathrm{mL}$ ) and HSCs survival (at 500 and $1000 \mathrm{ng} / \mathrm{mL}$ ) and protected against $\mathrm{H}_{2} \mathrm{O}_{2}$-induced DNA damage [36].

In another study by Halabian et al., treatment of BMSCs with Lipocalin-2 (Lcn2), a natural cytoprotective factor generated upon exposure to stressful conditions, increased cellular resistance against oxidative, hypoxic, and serum deprivation stresses. Moreover, Lcn2-treated cells showed SOD gene upregulation, increased proliferation, maintained pluripotency, and improved cellular adhesion to culture media upon $\mathrm{H}_{2} \mathrm{O}_{2}$ exposure, in comparison to untreated cells [37]. Similarly, Fan and colleagues studied different methods for isolation of BMSCs, aiming at reducing the number of chromosomal abnormalities in isolated cells. They reported that culturing isolated BMSCs at a low $\mathrm{O}_{2}$ concentration (2\%) or with antioxidant (NAC) supplementation increased cellular proliferation and genomic stability, in comparison to cultured cells at normoxic concentrations $\left(20 \% \mathrm{O}_{2}\right)$ [38].

Another study by Choi et al. demonstrated that adding ascorbic acid 2-phosphate (AAP) at different concentrations can influence the fate of BMSCs, that is, AAP significantly increased osteogenic differentiation at $50 \mathrm{mM}$ concentration, while a significant induction of adipogenic differentiation with oil droplet formation was noted at concentrations of $250 \mathrm{mM}$ and higher [39].

\section{Cardiomyoblasts and Vascular Progenitor Cells}

According to Li and colleagues, culturing cardiac stem cells with antioxidant increased the number and severity of cytogenic abnormalities. This could be explained by the excessive decrease in ROS to subphysiological levels, which may downregulate DNA repair enzymes [40]. In another study by Rodriguez-Porcel et al., modulation of the microenvironment, using antioxidants, leads to a higher rate of cardiomyoblast survival, early after transplantation to the myocardium of small animals [41]. Therefore, oxidative stress blockade may provide a favorable microenvironment for stem cells' engraftment and survival in the heart [42]. 
Song and colleagues reported increased ROS production during differentiation of human ESCs into vascular progenitor cells (CD34+ cells) due to increased activity of NADPH oxidase-4 (Nox4) enzyme. They found that moderate ROS scavenging, using selenium, enhanced the vascular differentiation of human ESCs, while complete ROS scavenging, using NAC, totally inhibited the vascular differentiation of these cells. This confirms that a minimal level of ROS is required for vascular stem cell differentiation to occur [43].

\section{Neural Stem Cells (NSCs)}

Neural stem cells are multipotent stem cells that have been suggested as a therapeutic agent to enhance the recovery of injured tissues in neuroinflammatory diseases [44]. Park and colleagues tested the effects of GV1001, a novel antioxidant agent, derived from human telomerase reverse transcriptase, on in vitro-cultured mouse NSCs. They showed that GV1001 treatment attenuated the effects of $\mathrm{H}_{2} \mathrm{O}_{2}$ exposure, reduced lipid peroxidation and mtDNA mutation, and induced the expression of survival-related proteins [45]. Hachem et al. reported that treatment of NSCs, isolated from the spinal cords of transgenic mice, with brain-derived neurotrophic factor improved cell viability by increasing the levels of GR and SOD enzymes; however, it had no effect on cellular proliferation [46].

Nitric oxide (NO) and nitric oxide synthase (NOS)dependent signaling pathways have been implicated in different neurodegenerative diseases $[47,48]$. Moreover, NO levels were linked to neural precursor cell (NPC) survival and cell fate determination [49], that is, elevated levels of NO suppress NSC proliferation and enhance differentiation of NPCs into astrocytes $[50,51]$. Melatonin is a hormone synthesized in the pineal gland [52] with indirect antioxidant abilities through induction of antioxidant enzymes [53] and inhibiting NO production in glial cultures through p38 inhibition [54]. It has been shown to protect NSCs against lipopolysaccharide- (LPS-) induced inflammation [52]. Moreover, Negi et al. demonstrated that melatonin mitigates neuroinflammation and oxidative stress via upregulating nuclear factor (erythroid-derived 2) (Nrf2) [55], a transcription factor which stimulates the PI3K-Akt survival signaling pathway $[56,57]$ and increases the expression of the antioxidant enzyme heme oxygenase-1 (HO-1) [55].

To test the effects of in vitro antioxidant supplementation, Petro et al. divided male rats with experimentally induced thromboembolic stroke into four groups: normal rats, untreated rats with stroke, rats receiving tissue plasminogen activator (tPA) only, and rats receiving tPA + CAT/ SOD (loaded on nanoparticles) at three hours post stroke. Two days later, brain tissue samples were harvested for analysis. Brain sections from the untreated group showed evidence of NSC migration through the rostral migratory stream (through detection of NSCs markers, such as nestin, GFAP, and SOX2), confirming the occurrence of neurogenesis following stroke. However, brain tissue samples from the tPA-alone group showed reduction in NSCs migration, indicating that tPA treatment suppresses neurogenesis, either directly or through reperfusion-induced
ROS generation injury. Interestingly, tPA + Nano-CAT/ SOD treatment restored and significantly increased NSCs migration [58].

\section{Human Adipose-Derived Stem Cells (ADSCs)}

Adipose-derived stem cells are multipotent stem cells that can be isolated from the human adipose tissue and are capable of in vitro expansion. Sun and colleagues reported that both hypoxia and antioxidants promoted ADSCs proliferation by raising the number of cells in the $S$ phase, but the maximal increase in cell number was produced in the presence of antioxidants [59]. Hypoxia is believed to influence the secretion of several growth factors [60, 61], such as insulin-like growth factor and hepatocyte growth factor [62], while antioxidants increase the expression of stemness genes (CDK2, CDK4, and CDC2) and the differentiation potential of ADSCs [59]. Another study by Higuchi et al. found that lentivirus-mediated NADPH oxidase-4 (Nox-4) overexpression did not increase ROS production in insulin, dexamethasone, indomethacin, and 3-isobutyl-1-methylxanthine (IDII)-stimulated ADSCs [63]. This finding was later explained by the increased expression of endogenous antioxidants, such as SOD and CAT during adipogenesis [63, 64].

Yang et al. showed that treatment of ADSCs with fullerol (a polyhydroxylated fullerene) potentiated the expression of the transcription factor FoxO1 and its downstream genes, such as Runx2 and SOD2. Moreover, it enhanced the osteogenic activity of ADSCs, as evidenced by increased mineralization and expression of osteogenic markers (Runx2, OCN, and alkaline phosphatase) [65]. Wang and colleagues showed that pretreatment of ADSCs with NAC $(3 \mathrm{mM})$ or AAP $(0.2 \mathrm{mM})$ for 20 hours suppressed advanced glycosylation end product- (AGE-) induced apoptosis via a microRNAdependent mechanism by inhibiting AGE-induced overexpression of miRNA-223: a key modulator of intracellular apoptotic signaling [66].

\section{Human Periodontal Ligament Cells (hPDLCs)}

In a recent study, Chung and colleagues showed that treating hPDLCs with deferoxamine (DFO), an iron chelator, results in a dose-dependent elevation in ROS levels, 24 hours after treatment [67]. The same finding was reported in rabbit cardiomyocytes [68] and normal human hepatocytes [69]. However, DFO has the ability to act on Nrf2, increasing its nuclear translocation and the expression of its target genes, including GST and glutamate cysteine ligase (GCL) [67]. Therefore, DFO has both beneficial (Nrf2-mediated antioxidant effect) and cytotoxic (increased ROS levels) effects. GSH depletion, using buthionine sulfoximine (BSO) and diethyl maleate (DEM), was shown to inhibit DFO-stimulated hPDLC differentiation into osteoblasts [67]. Moreover, GSH depletion was also reported to repress myogenic differentiation of murine skeletal muscle (C2C12) cells [70] and phorbol-12-myristate-13-acetate- (PMA-) stimulated differentiation of human myeloid cell line (HL-60) [71]. 


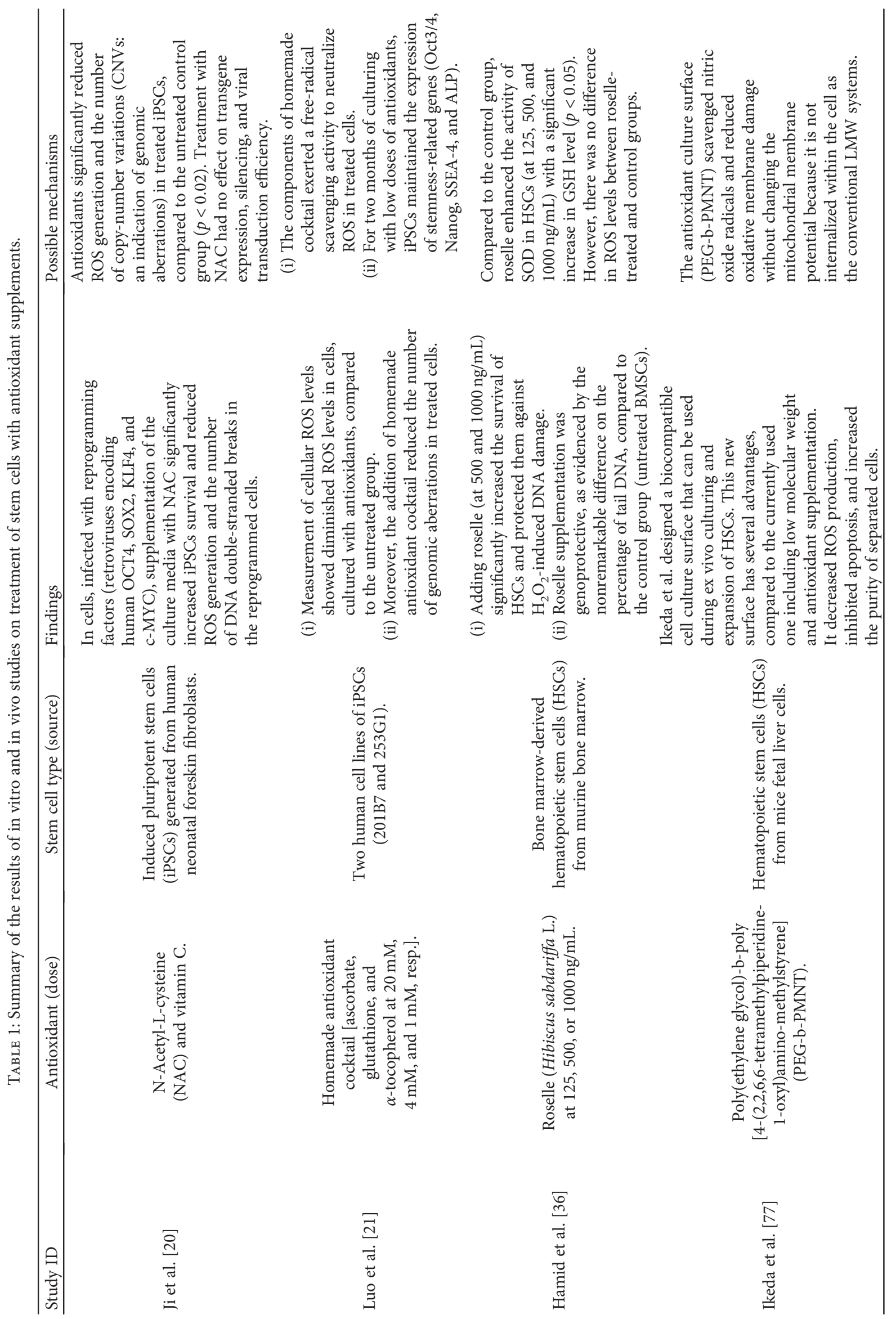




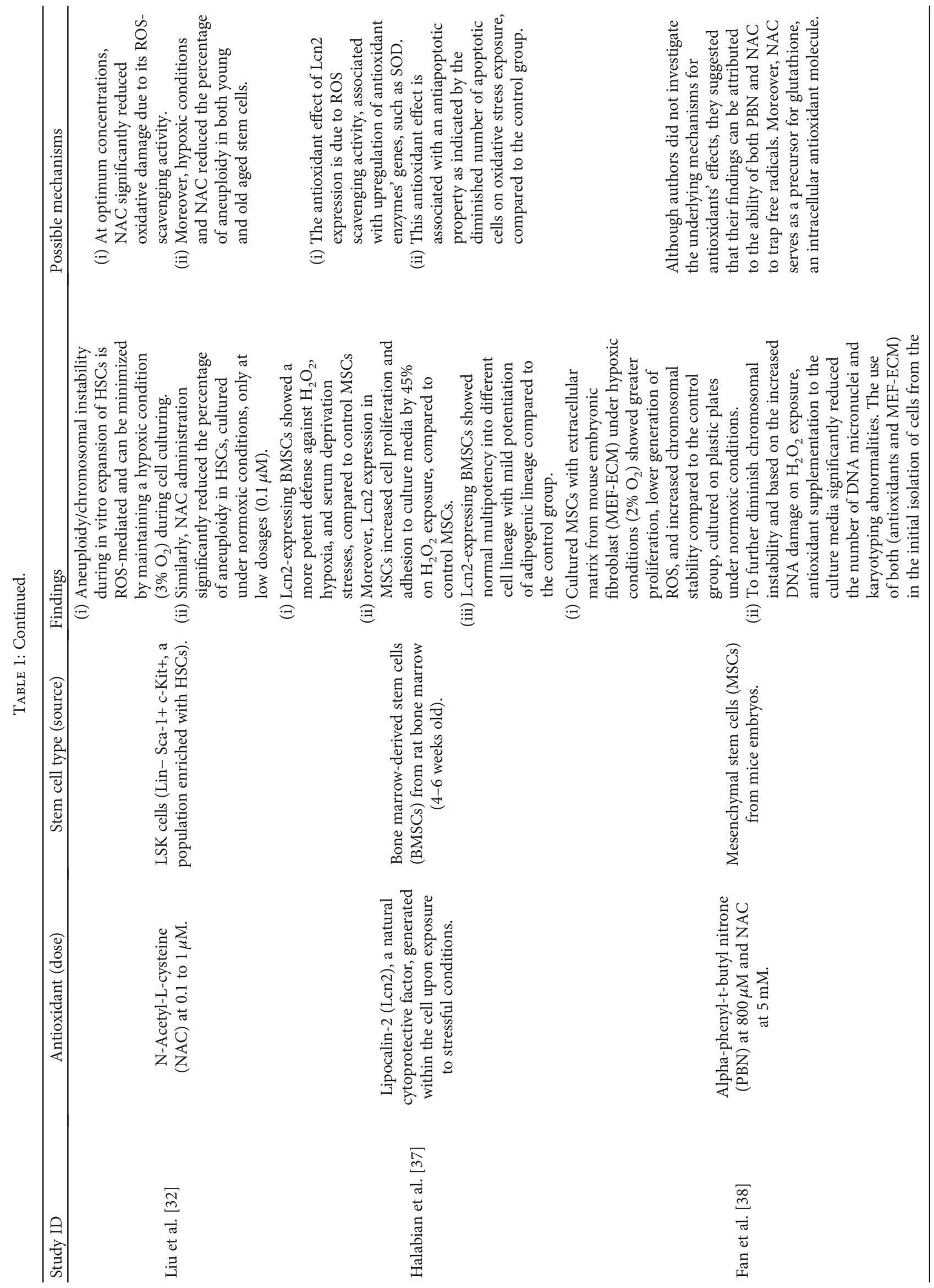




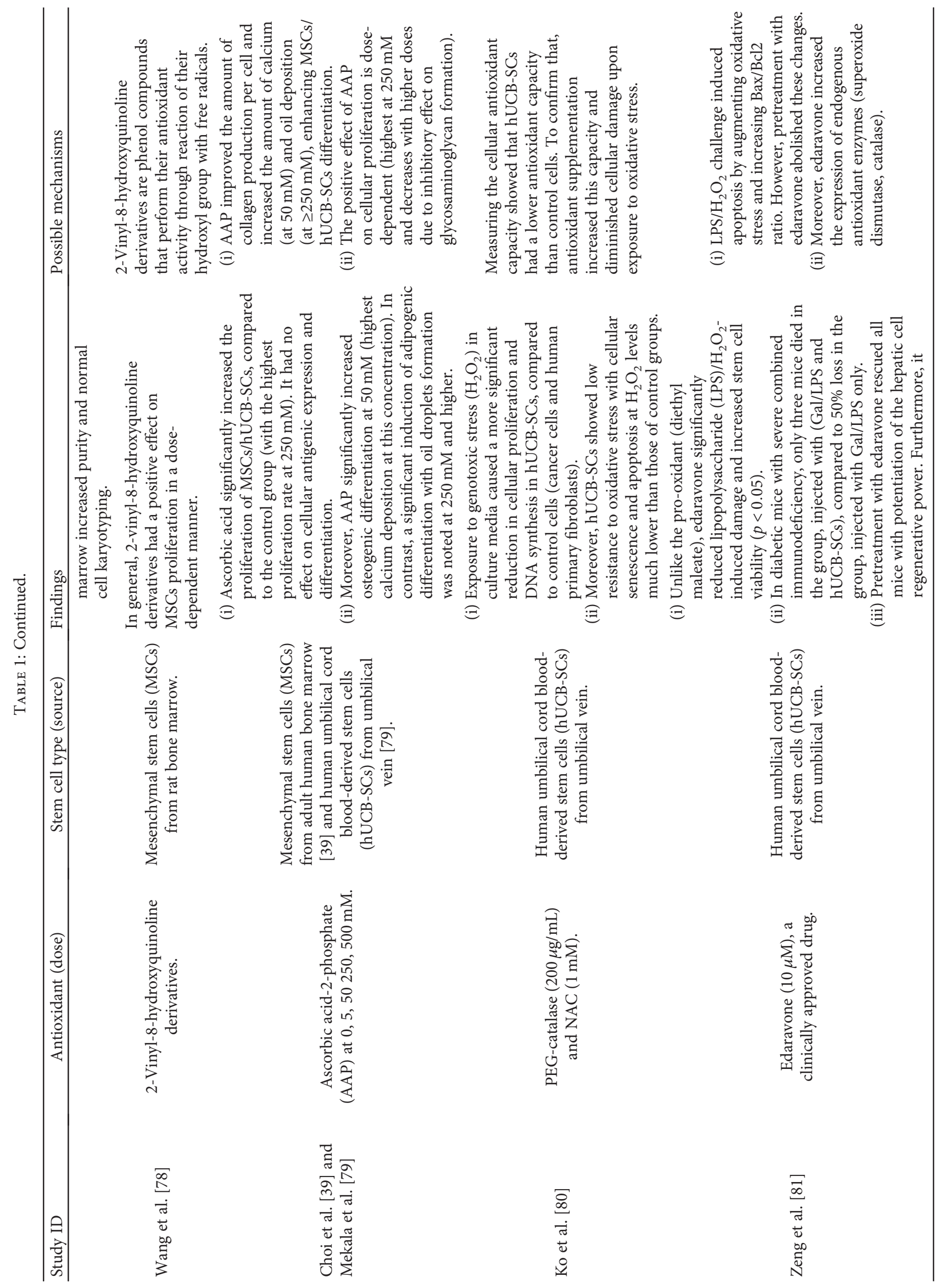




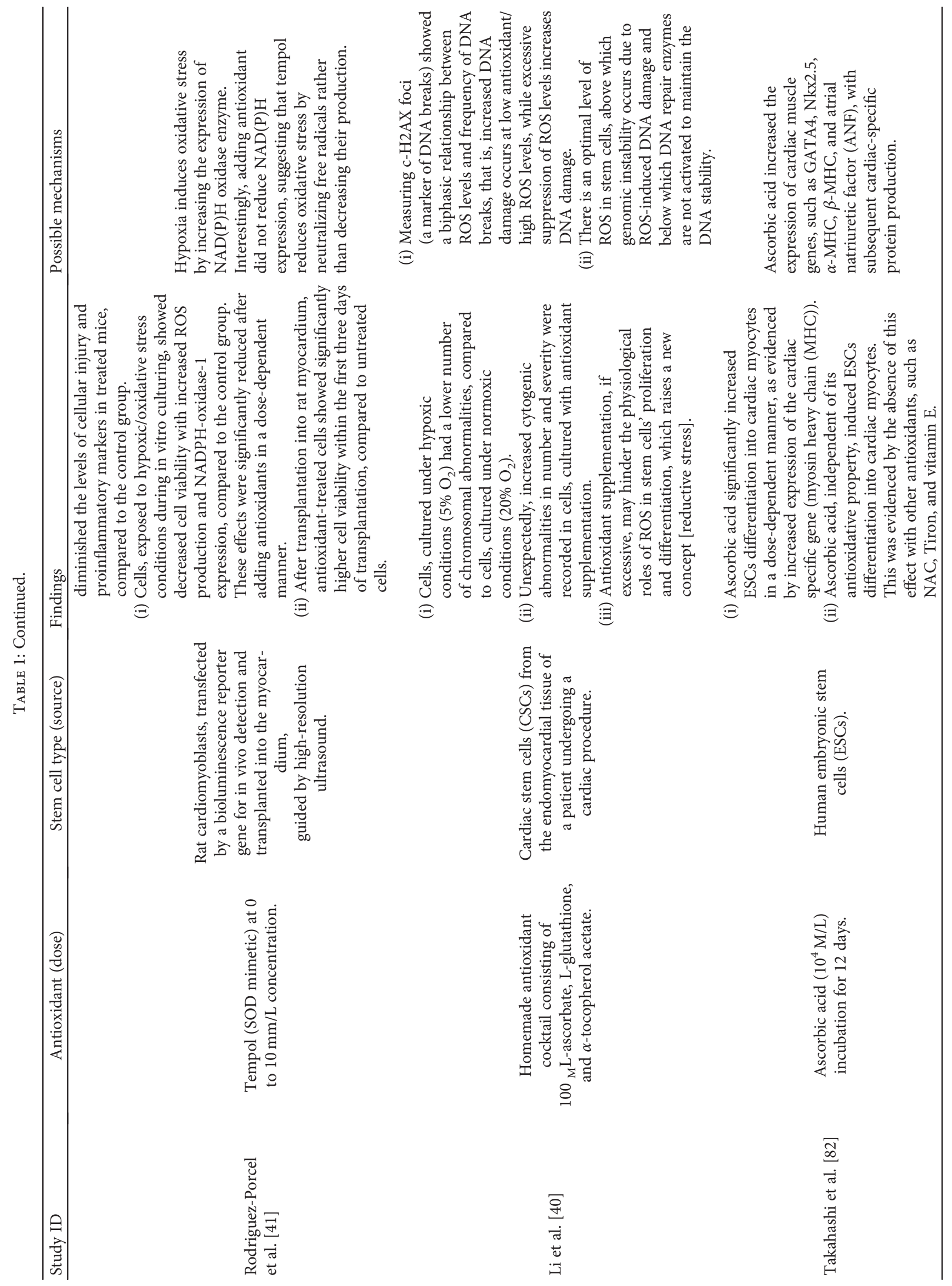




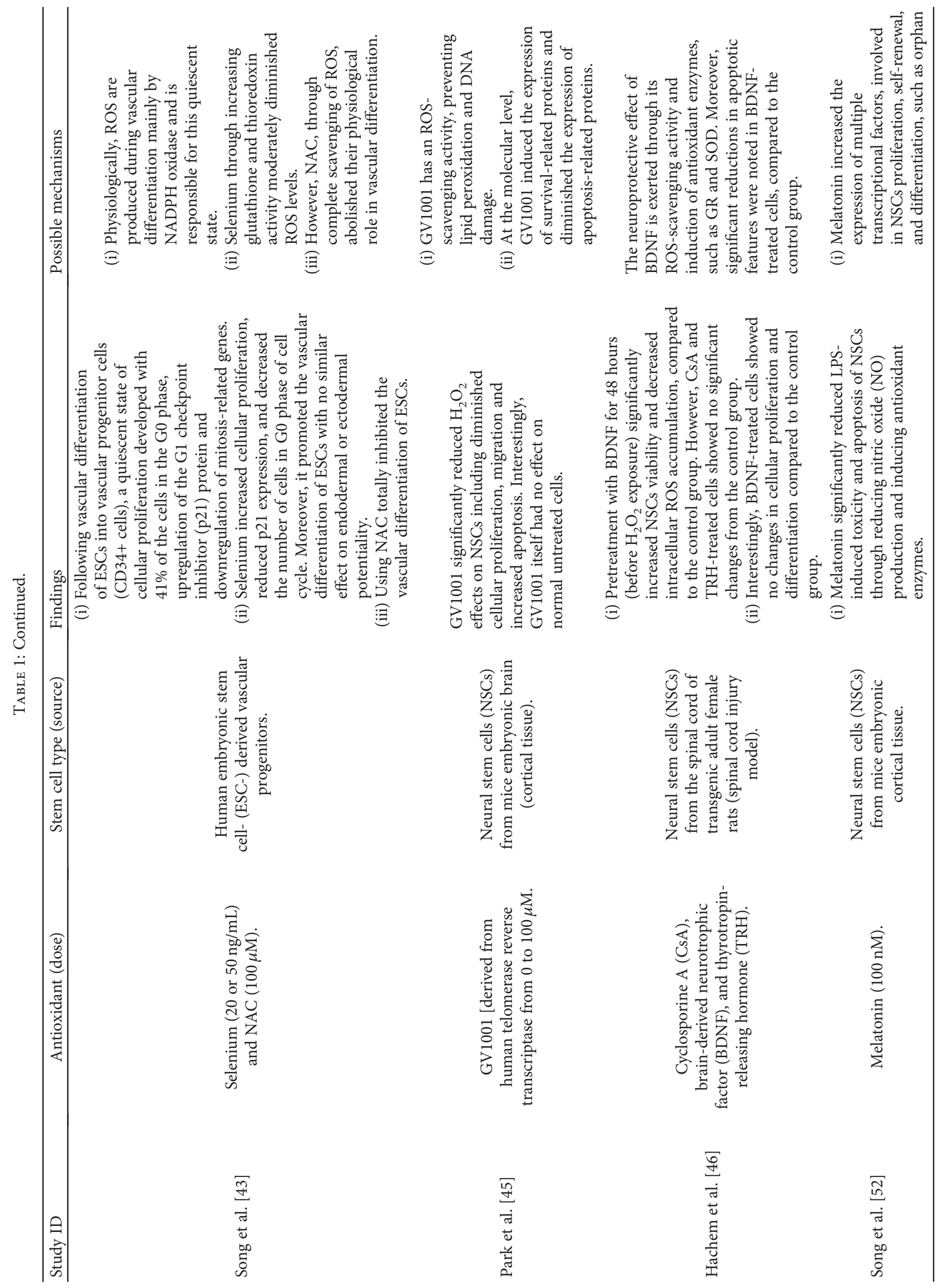




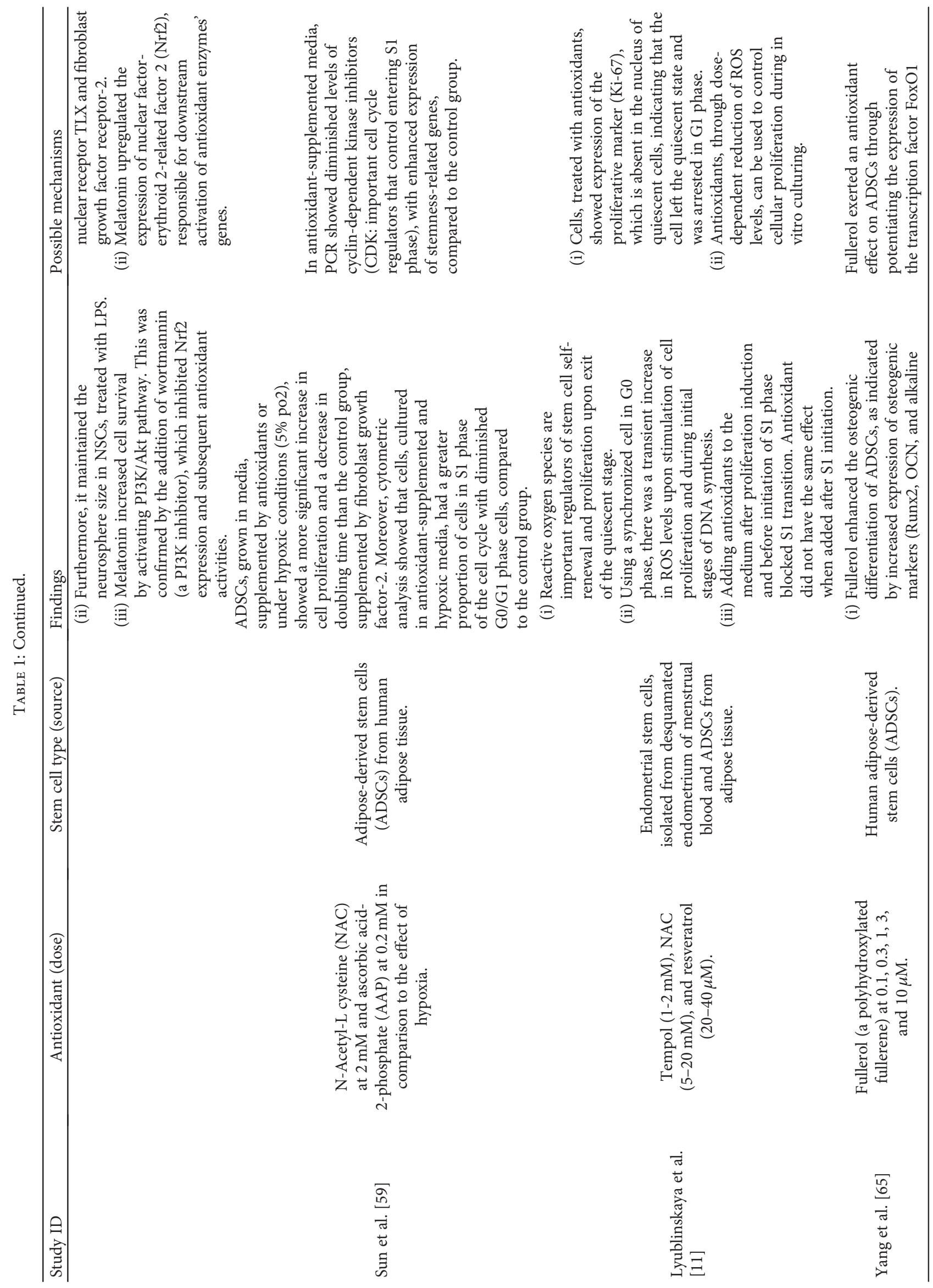




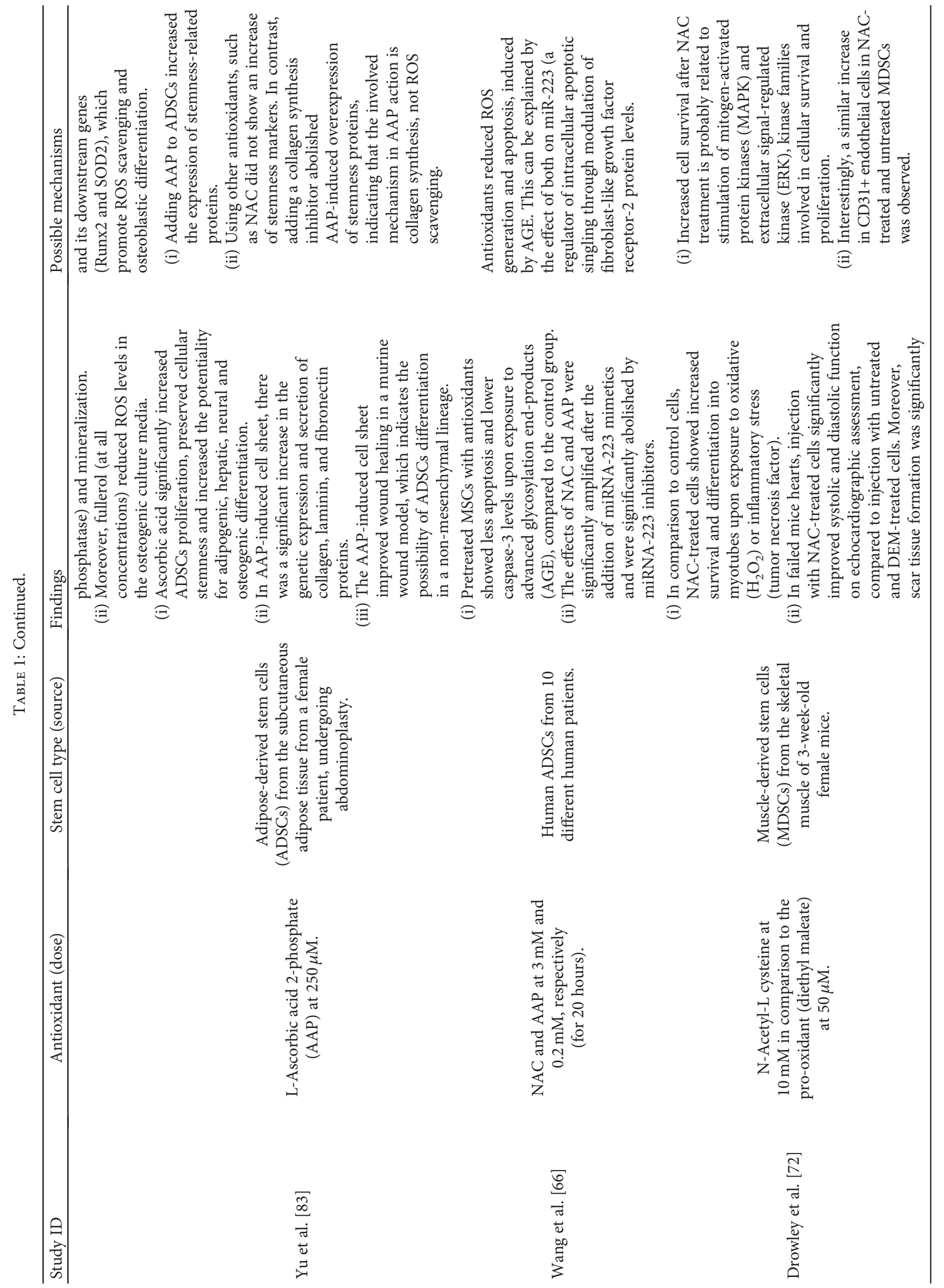




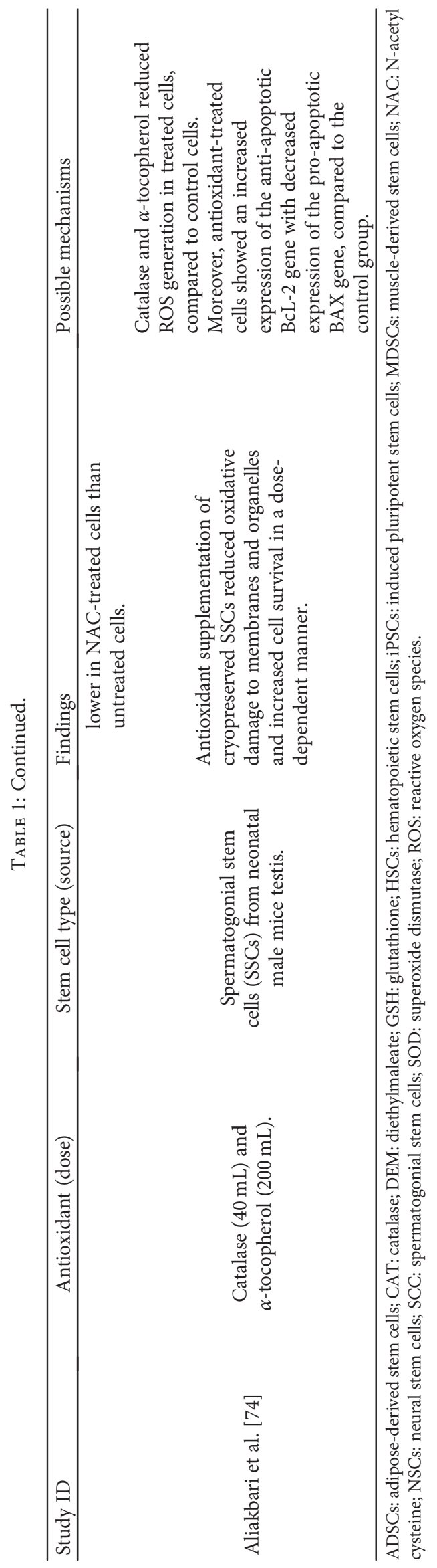




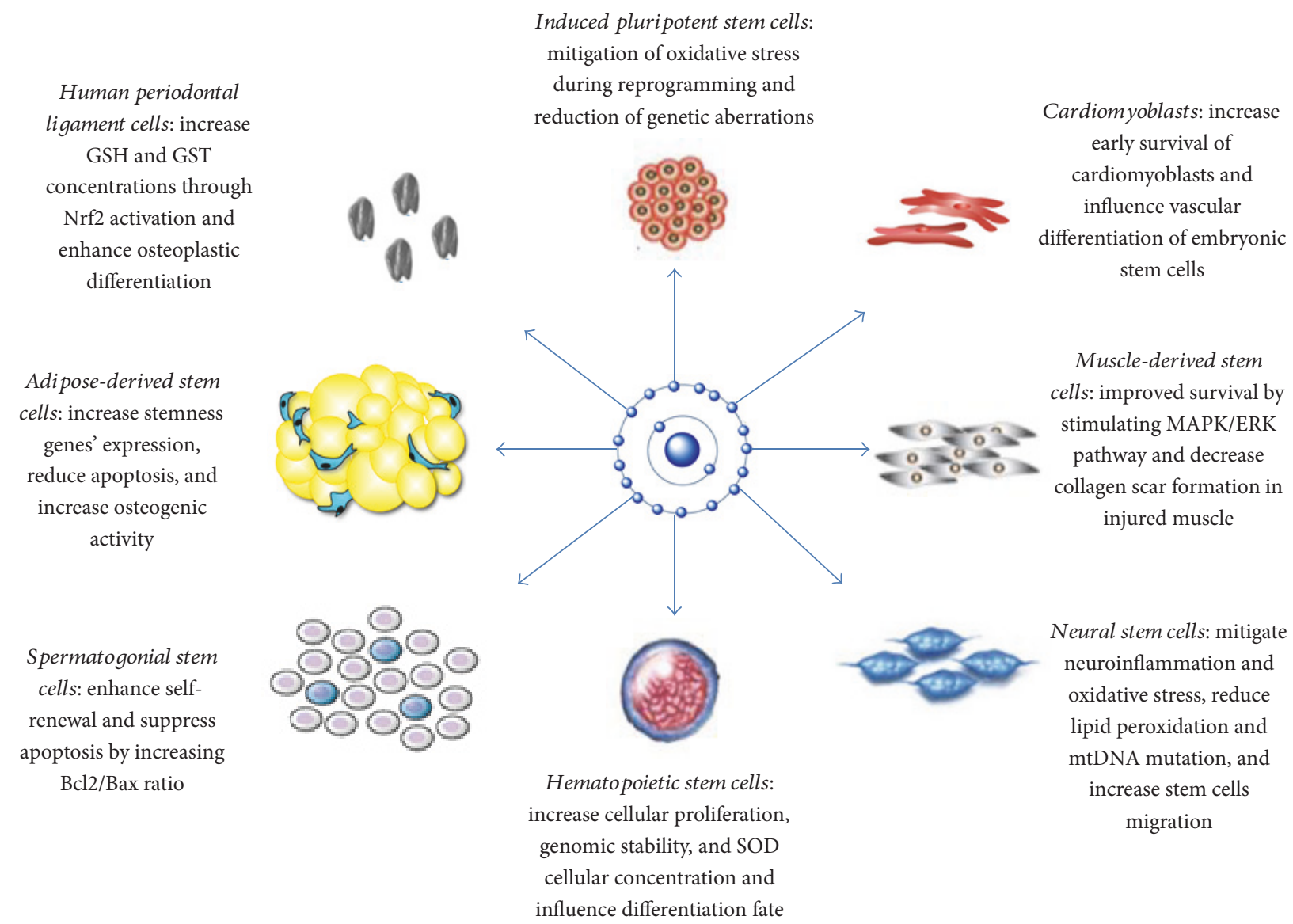

Figure 1: Summarizes the effects of antioxidants on different types of stem cells.

\section{Muscle-Derived Stem Cells (MDSCs)}

According to Drowley and colleagues, injection of injured skeletal muscles with NAC-treated MDSCs significantly increased muscle regeneration, compared to muscles injected with untreated or DEM-treated MDSCs. The direction of scar tissue formation was opposite the direction of the host muscle regeneration [72]. Additionally, they showed an improved survival of NAC-treated MDSCs, probably due to stimulation of extracellular signal-regulated kinase (ERK) pathway, as evidenced by decreased survival of NAC treated cells after inhibition of the ERK pathway $[72,73]$.

Moreover, they demonstrated that experimentally infarcted hearts, injected with NAC-treated MDSCs, showed a more significant reduction in the percentage area of collagenous scar tissue than hearts injected with either untreated, DEM-treated, or phosphate buffered saline- (PBS-) treated MDSCs. There was no difference in myocardial scar formation between hearts injected with DEM-treated MDSCs and those injected with PBS [72].

\section{Spermatogonia Stem Cells (SSCs)}

Cryopreservation of spermatogonial stem cells, in the presence of catalase (CAT) and $\alpha$-tocopherol ( $\alpha$-TCP), promoted cell viability and suppressed apoptosis through inducing the expression of the antiapoptotic BcL-2 gene and inhibiting the expression of the proapoptotic BAX gene [74]. In other studies, cryopreservation with antioxidants could promote cell enrichment and increase the efficiency of colony formation in isolated SSCs $[75,76]$. Spermatogonia-derived colonies showed increased SSC marker activity, enhanced expression of self-renewal genes, such as promyelocytic leukemia zinc finger (Plzf) protein and DNA-binding protein inhibitor ID4, and suppressed expression of the protooncogene (c-kit) in both CAT and $\alpha$-TCP treated groups [74]. This technique can increase the possibility of SSCs banking for men with malignant diseases and promote the resumption of spermatogenesis in SCCs recipients. A summary of the design and main findings of included studies is illustrated in Table 1.

\section{Discussion}

Our review highlights that antioxidants can influence stem cell activities by [1] mitigating oxidative stress through neutralization of free radicals and increasing the expression of antioxidant enzymes and [2] influencing the differentiation fate of precursor stem cells. Further beneficial effects of antioxidant treatment include increasing genomic stability, improving the adhesion of stem cells to culture media, and enabling researchers to manipulate stem cell proliferation by using different doses of antioxidants. Figure 1 summarizes the effects of antioxidants on different types of stem cells. 
We also discussed that a physiological level of ROS (oxidative optimum) is needed for proper differentiation of stem cells, especially for proper cardiogenesis and vasculogenesis [40]. These findings can have several clinical applications, such as improving neurogenesis in patients with stroke and neurodegenerative diseases, as well as improving the regeneration of infarcted myocardial tissue and the banking of SCCs.

Antioxidants are prevalent supplements worldwide. However, little is known about their cell-type-specific actions. It has been shown that a therapeutic dose may vary between different cell types: a dose that rescues a pathology in one tissue may roughly challenge the function of another [22]. Therefore, there is a need for dose-effect studies on antioxidants to confirm their safety as nutritional supplements or therapeutic agents-particularly in the case of antioxidants accumulating in the mitochondria. Our review also showed the potential of some endogenous molecules, such as melatonin, BDNF, and the adipokine (lipocalin-2) in preserving stem cell viability and differentiation potential. Whether these compounds can be used in future clinical applications of stem cells and whether other endogenous molecules with proven antioxidant activities, such as adiponectin [84], can be useful in this regard require further investigation.

\section{Recommendations}

(1) Multiplicity of stem cell sources within the body (different home environments) and their variable ROS scavenging capacity make them susceptible to oxidative stress at different thresholds. Therefore, we tried to review each stem cell type as a separate entity and we believe that clearing those differences on the molecular and genetic levels will optimize the clinical application of stem cells in different medical fields.

(2) Most of stem cell characteristics are established within in vitro culturing environments. More in vivo studies are required to define their interactions within the body. Furthermore, few in vivo studies have focused on the long-term survival of transplanted stem cells; therefore, this should be the interest of future studies.

(3) The effect of ROS level and redox state on the longterm oncogenicity of stem cells should be further investigated prior to in vivo clinical trials.

\section{Conclusion}

Using antioxidants can improve the viability and self-renewal capacity of stem cells and affect their differentiation potential. More research is needed on the dose-effect association and cell-type-specific actions of antioxidant before applying these findings in human therapeutic trials.

\section{Abbreviations}

ADSCs: Adipose-derived stem cells

BMSCs: Bone marrow-derived mesenchymal stem cells
CAT: Catalase

DEM: Diethylmaleate

DFO: Deferoxamine

GSH: Glutathione

hPDLCs: Human periodontal ligament cells

HSCs: Hematopoietic stem cells

iPSCs: Induced pluripotent stem cells

MDSCs: Muscle-derived stem cells

NAC: N-acetyl cysteine

NSCs: Neural stem cells

PBP: $\quad$ Phosphate buffered saline

SCCs: Spermatogonial stem cells

SOD: Superoxide dismutase

ROS: $\quad$ Reactive oxygen species.

\section{Conflicts of Interest}

The authors declare that they have no conflicts of interest.

\section{Authors' Contributions}

Sara Shaban, Mostafa Wanees Ahmed El-Husseny, and Abdelrahman Ibrahim Abushouk contributed equally to this work.

\section{References}

[1] J. Thomson and J. Odorico, "Human embryonic stem cell and embryonic germ cell lines," Trends in Biotechnology, vol. 18, no. 2, pp. 53-57, 2000.

[2] N. Knoepffler, D. Schipanski, and S. L. Sorgner, Humanbiotechnology as Social Challenge: An Interdisciplinary Introduction to Bioethics, Ashgate, Farnham, Surrey, United Kingdom, 2007.

[3] B. Vastag, "Stem cells step closer to the clinic," Jama, vol. 285, no. 13, p. 1691, 2001, American Medical Association.

[4] M. Izumikawa, R. Minoda, K. Kawamoto et al., "Auditory hair cell replacement and hearing improvement by Atoh1 gene therapy in deaf mammals," Nature Medicine, vol. 11, no. 3, pp. 271-276, 2005.

[5] S. D. Narasipura, J. C. Wojciechowski, N. Charles, J. L. Liesveld, and M. R. King, "P-selectin-coated microtube for enrichment of CD34+ hematopoietic stem and progenitor cells from human bone marrow," Clinical Chemistry, vol. 54, no. 1, pp. 77-85, 2007.

[6] M. Witkowska-Zimny and K. Walenko, "Stem cells from adipose tissue," Cellular and Molecular Biology Letters, vol. 16, no. 2, pp. 236-257, 2011.

[7] M. A. Esteban, T. Wang, B. Qin et al., "Vitamin C enhances the generation of mouse and human induced pluripotent stem cells," Cell Stem Cell, vol. 6, no. 1, pp. 71-79, 2010.

[8] M. Stadtfeld, E. Apostolou, F. Ferrari, J. Choi, and R. Walsh, "Ascorbic acid prevents loss of Dlk1-Dio3 imprinting and facilitates generation of all-iPS cell mice from terminally differentiated B cells," Nature, vol. 44, no. 4, pp. 398-405, 2012.

[9] W. Neeley and J. Essigmann, "Mechanisms of formation, genotoxicity, and mutation of guanine oxidation products," Chemical Research in Toxicology, vol. 19, no. 4, pp. 491-505, 2006.

[10] J. Silva and O. Coutinho, "Free radicals in the regulation of damage and cell death-basic mechanisms and prevention," Drug Discoveries \& Therapeutics, vol. 4, no. 3, pp. 144-167, 2010. 
[11] O. G. Lyublinskaya, Y. G. Borisov, N. A. Pugovkina et al., "Reactive oxygen species are required for human mesenchymal stem cells to initiate proliferation after the quiescence exit," Oxidative Medicine and Cellular Longevity, vol. 2015, Article ID 502105, 8 pages, 2015.

[12] B. J. Le, N. Orozco, A. Paucar, and J. Saxe, "Proliferative neural stem cells have high endogenous ROS levels that regulate selfrenewal and neurogenesis in a PI3K/Akt-dependant manner," Cell Stem Cell, vol. 8, no. 1, pp. 59-71, 2011.

[13] C. Kobayashi and T. Suda, "Regulation of reactive oxygen species in stem cells and cancer stem cells," Journal of Cellular Physiology, vol. 227, no. 2, pp. 421-430, 2012.

[14] C. Pérez Estrada, R. Covacu, S. R. Sankavaram, M. Svensson, and L. Brundin, "Oxidative stress increases neurogenesis and oligodendrogenesis in adult neural progenitor cells," Stem Cells and Development, vol. 23, no. 19, pp. 2311-2327, 2014.

[15] S. Kothari, A. Thompson, A. Agarwal, and S. S. du Plessis, "Free Radicals: Their Beneficial and Detrimental Effects on Sperm Function," Indian Journal of Experimental Biology, vol. 48, no. 5, pp. 425-435, 2010.

[16] S. Vertuani, A. Angusti, and S. Manfredini, "The antioxidants and pro-antioxidants network: an overview," Current Pharmaceutical Design, vol. 10, no. 14, pp. 1677-1694, 2004.

[17] H. Sies, "Oxidative stress: oxidants and antioxidants," Experimental Physiology, vol. 82, no. 2, pp. 291-295, 1997.

[18] B. Dannenmann, S. Lehle, F. Essmann, and K. Schulze-Osthoff, "Genome surveillance in pluripotent stem cells: low apoptosis threshold and efficient antioxidant defense," Molecular \& Cellular Oncology, vol. 3, no. 2, article e1052183, 2016, Taylor \& Francis.

[19] B. Dannenmann, S. Lehle, D. G. Hildebrand et al., "High glutathione and glutathione peroxidase-2 levels mediate cell-typespecific DNA damage protection in human induced pluripotent stem cells," Stem Cell Reports, vol. 4, no. 5, pp. 886-898, 2015.

[20] J. Ji, V. Sharma, S. Qi et al., "Antioxidant supplementation reduces genomic aberrations in human induced pluripotent stem cells," Stem Cell Reports, vol. 2, no. 1, pp. 44-51, 2014.

[21] L. Luo, M. Kawakatsu, C.-W. Guo et al., "Effects of antioxidants on the quality and genomic stability of induced pluripotent stem cells," Scientific Reports, vol. 4, p. 3779, 2014, Nature Publishing Group.

[22] R. H. Hämäläinen, K. J. Ahlqvist, P. Ellonen et al., "mtDNA mutagenesis disrupts pluripotent stem cell function by altering redox signaling," Cell Reports, vol. 11, no. 10, pp. 1614-1624, 2015.

[23] A. M. Sadowska, B. Manuel-y-Keenoy, and W. A. De Backer, "Antioxidant and anti-inflammatory efficacy of NAC in the treatment of COPD: discordant in vitro and in vivo doseeffects: a review," Pulmonary Pharmacology \& Therapeutics, vol. 20, no. 1, pp. 9-22, 2007.

[24] G. F. Kelso, C. M. Porteous, C. V. Coulter et al., "Selective targeting of a redox-active ubiquinone to mitochondria within cells: antioxidant and antiapoptotic properties," The Journal of Biological Chemistry, vol. 276, no. 7, pp. 45884596, 2001, American Society for Biochemistry and Molecular Biology.

[25] T. Kinoshita, G. Nagamatsu, T. Kosaka et al., "Ataxia-telangiectasia mutated (ATM) deficiency decreases reprogramming efficiency and leads to genomic instability in iPS cells," Biochemical and Biophysical Research Communications, vol. 407, no. 2, pp. 321-326, 2011.
[26] R. Kitagawa and M. B. Kastan, "The ATM-dependent DNA damage signaling pathway," Cold Spring Harbor Symposia on Quantitative Biology, vol. 70, no. 1, pp. 99-109, 2005, Cold Spring Harbor Laboratory Press.

[27] A. T. Noon and A. A. Goodarzi, "53BP1-mediated DNA double strand break repair: insert bad pun here," DNA Repair, vol. 10, no. 10, pp. 1071-1076, 2011.

[28] D. Foudah, S. Redaelli, E. Donzelli et al., "Monitoring the genomic stability of in vitro cultured rat bone-marrowderived mesenchymal stem cells," Chromosome Research, vol. 17, no. 8, pp. 1025-1039, 2009, Springer Netherlands.

[29] Y. F. Zhou, M. Bosch-Marce, H. Okuyama et al., "Spontaneous transformation of cultured mouse bone marrow-derived stromal cells," Cancer Research, vol. 66, no. 22, pp. 10849-10854, 2006.

[30] D. E. C. Baker, N. J. Harrison, E. Maltby et al., “Adaptation to culture of human embryonic stem cells and oncogenesis in vivo," Nature Biotechnology, vol. 25, no. 2, pp. 207-215, 2007, Nature Publishing Group.

[31] A. Maitra, D. E. Arking, N. Shivapurkar et al., "Genomic alterations in cultured human embryonic stem cells," Nature Genetics, vol. 37, no. 10, pp. 1099-1103, 2005, Nature Publishing Group.

[32] A. M. Liu, W. W. Qu, X. Liu, and C.-K. Qu, "Chromosomal instability in in vitro cultured mouse hematopoietic cells associated with oxidative stress," American Journal of Blood Research, vol. 2, no. 1, pp. 71-76, 2012, e-Century Publishing Corporation.

[33] Y.-Y. Jang and S. J. Sharkis, "A low level of reactive oxygen species selects for primitive hematopoietic stem cells that may reside in the low-oxygenic niche," Blood, vol. 110, no. 8, pp. 3056-3063, 2007.

[34] P. Eliasson, M. Rehn, P. Hammar et al., "Hypoxia mediates low cell-cycle activity and increases the proportion of long-termreconstituting hematopoietic stem cells during in vitro culture," Experimental Hematology, vol. 38, no. 4, pp. 301-310.e2, 2010.

[35] G. H. Danet, Y. Pan, J. L. Luongo, D. A. Bonnet, and M. C. Simon, "Expansion of human SCID-repopulating cells under hypoxic conditions," The Journal of Clinical Investigation, vol. 112, no. 1, pp. 126-135, 2003, American Society for Clinical Investigation.

[36] Z. A. Hamid, W. Hii, L. Lin et al., "The role of Hibiscus sabdariffa L. (roselle) in maintenance of ex vivo murine bone marrow-derived hematopoietic stem cells," The Scientific World Journal, vol. 2014, Article ID 258192, 10 pages, 2014.

[37] R. Halabian and H. A. Tehrani, "Lipocalin-2-mediated upregulation of various antioxidants and growth factors protects bone marrow-derived mesenchymal stem cells against unfavorable microenvironments," Cell Stress and Chaperones, vol. 18, no. 6, pp. 785-800, 2013.

[38] G. Fan, L. Wen, M. Li et al., "Isolation of mouse mesenchymal stem cells with normal ploidy from bone marrows by reducing oxidative stress in combination with extracellular matrix," BMC Cell Biology, vol. 12, no. 1, p. 30, 2011.

[39] K. Choi, Y. Seo, H. Yoon et al., "Effect of ascorbic acid on bone marrow-derived mesenchymal stem cell proliferation and differentiation," Journal of Bioscience and Bioengineering, vol. 105, no. 6, pp. 586-594, 2008.

[40] T. S. Li and E. Marbán, "Physiological levels of reactive oxygen species are required to maintain genomic stability in stem cells," Stem Cells, vol. 28, no. 7, pp. 1178-1185, 2010. 
[41] M. Rodriguez-Porcel, O. Gheysens, R. Paulmurugan et al., "Antioxidants improve early survival of cardiomyoblasts after transplantation to the myocardium," Molecular Imaging and Biology, vol. 12, no. 3, pp. 325-334, 2010, Springer-Verlag.

[42] C. Napoli, S. Williams-Ignarro, F. de Nigris et al., "Beneficial effects of concurrent autologous bone marrow cell therapy and metabolic intervention in ischemia-induced angiogenesis in the mouse hindlimb," Proceedings of the National Academy of Sciences of the United States of America, vol. 102, no. 47, pp. 17202-17206, 2005, National Academy of Sciences.

[43] S. Song, K. Kim, J. J. Park, K. H. Min, and W. Suh, "Reactive oxygen species regulate the quiescence of CD34-positive cells derived from human embryonic stem cells," Cardiovascular Research, vol. 103, no. 1, pp. 1-29, 2014.

[44] M. Song, Y.-J. Kim, Y.-H. Kim, J. Roh, S. U. Kim, and B.-W. Yoon, "Effects of duplicate administration of human neural stem cell after focal cerebral ischemia in the rat," International Journal of Neuroscience, vol. 121, no. 8, pp. 457-461, 2011, Taylor \& Francis.

[45] H. H. Park, H. J. Yu, K. Sangjae et al., "Neural stem cells injured by oxidative stress can be rejuvenated by GV1001, a novel peptide, through scavenging free radicals and enhancing survival signals," Neurotoxicology, vol. 55, pp. 131-141, 2016, Elsevier B.V.

[46] L. D. Hachem, A. J. Mothe, and C. H. Tator, "Effect of BDNF and other potential survival factors in models of in vitro oxidative stress on adult spinal cord-derived neural stem/progenitor cells," BioResearch Open Access, vol. 4, no. 1, pp. 146-159, 2015.

[47] A. A. Pieper, S. Blackshaw, E. E. Clements et al., "Poly(ADPribosyl)ation basally activated by DNA strand breaks reflects glutamate-nitric oxide neurotransmission," Proceedings of the National Academy of Sciences of the United States of America, vol. 97, no. 4, pp. 1845-1850, 2000, National Academy of Sciences.

[48] V. Calabrese, T. E. Bates, and A. M. G. Stella, "NO synthase and NO-dependent signal pathways in brain aging and neurodegenerative disorders: the role of oxidant/antioxidant balance," Neurochemical Research, vol. 25, no. 9/10, pp. 13151341, 2000, Kluwer Academic Publishers-Plenum Publishers.

[49] A. Cheng, S. L. Chan, O. Milhavet, S. Wang, and M. P. Mattson, "p38 MAP kinase mediates nitric oxide-induced apoptosis of neural progenitor cells," The Journal of Biological Chemistry, vol. 276, no. 46, pp. 43320-43327, 2001, American Society for Biochemistry and Molecular Biology.

[50] R. Covacu, A. I. Danilov, B. S. Rasmussen et al., "Nitric oxide exposure diverts neural stem cell fate from neurogenesis towards astrogliogenesis," Stem Cells, vol. 24, no. 12, pp. 2792-2800, 2006, John Wiley \& Sons, Ltd.

[51] A. Torroglosa, M. Murillo-Carretero, C. Romero-Grimaldi, E. R. Matarredona, A. Campos-Caro, and C. Estrada, "Nitric oxide decreases subventricular zone stem cell proliferation by inhibition of epidermal growth factor receptor and phosphoinositide-3-kinase/Akt pathway," Stem Cells, vol. 25, no. 1, pp. 88-97, 2007, John Wiley \& Sons, Ltd.

[52] J. Song, S. M. Kang, K. M. Lee, and J. E. Lee, “The protective effect of melatonin on neural stem cell against LPS-induced inflammation," BioMed Research International, vol. 2015, Article ID 854359, 13 pages, 2015, Hindawi Publishing Corporation.

[53] C. Tomás-Zapico and A. Coto-Montes, "A proposed mechanism to explain the stimulatory effect of melatonin on antioxidative enzymes," Journal of Pineal Research, vol. 39, no. 2, pp. 99-104, 2005, Munksgaard International Publishers.

[54] A. Vilar, L. de Lemos, I. Patraca et al., "Melatonin suppresses nitric oxide production in glial cultures by pro-inflammatory cytokines through p38 MAPK inhibition," Free Radical Research, vol. 48, no. 2, pp. 119-128, 2014, Taylor \& Francis.

[55] G. Negi, A. Kumar, and S. S. Sharma, "Melatonin modulates neuroinflammation and oxidative stress in experimental diabetic neuropathy: effects on NF- $\kappa \mathrm{B}$ and Nrf2 cascades," Journal of Pineal Research, vol. 50, no. 2, pp. 124-131, 2010, Blackwell Publishing Ltd.

[56] Q. Ma, "Role of nrf2 in oxidative stress and toxicity. Annual review of pharmacology and toxicology," NIH Public Access, vol. 53, pp. 401-426, 2013.

[57] Y.-J. Surh, J. K. Kundu, M.-H. Li, H.-K. Na, and Y.-N. Cha, "Role of Nrf2-mediated heme oxygenase-1 upregulation in adaptive survival response to nitrosative stress," Archives of Pharmacal Research, vol. 32, no. 8, pp. 1163-1176, 2009, Pharmaceutical Society of Korea.

[58] M. Petro, H. Jaffer, J. Yang, S. Kabu, V. B. Morris, and V. Labhasetwar, "Biomaterials tissue plasminogen activator followed by antioxidant-loaded nanoparticle delivery promotes activation/mobilization of progenitor cells in infarcted rat brain," Biomaterials, vol. 81, pp. 169-180, 2016, Elsevier Ltd.

[59] L.-Y. Sun, C.-Y. Pang, D.-K. Li et al., “Antioxidants cause rapid expansion of human adipose-derived mesenchymal stem cells via CDK and CDK inhibitor regulation," Journal of Biomedical Science, vol. 20, no. 1, p. 53, 2013, BioMed Central.

[60] K. Tamama, H. Kawasaki, S. S. Kerpedjieva, J. Guan, R. K. Ganju, and C. K. Sen, "Differential roles of hypoxia inducible factor subunits in multipotential stromal cells under hypoxic condition," Journal of Cellular Biochemistry, vol. 112, no. 3, pp. 804-817, 2011, Wiley Subscription Services, Inc., A Wiley Company.

[61] S.-P. Hung, J. H. Ho, and Y.-R. V. ShihT. Lo and O. K. Lee, "Hypoxia promotes proliferation and osteogenic differentiation potentials of human mesenchymal stem cells," Journal of Orthopaedic Research, vol. 30, no. 2, pp. 260-266, 2012, Wiley Subscription Services, Inc., A Wiley Company.

[62] I. Martin, A. Muraglia, G. Campanile, R. Cancedda, and R. Quarto, "Fibroblast growth factor-2 supports ex vivo expansion and maintenance of osteogenic precursors from human bone marrow," Endocrinology, vol. 138, no. 10, pp. 44564462, 1997, Endocrine Society.

[63] M. Higuchi, G. J. Dusting, H. Peshavariya et al., "Differentiation of human adipose-derived stem cells into fat involves reactive oxygen species and forkhead box $\mathrm{O} 1$ mediated upregulation of antioxidant enzymes," Stem Cells and Development, vol. 22, no. 6, pp. 878-888, 2013, Mary Ann Liebert, Inc. 140 Huguenot Street, 3rd Floor New Rochelle, NY 10801 USA.

[64] T. Kojima, T. Norose, K. Tsuchiya, and K. Sakamoto, "Mouse 3T3-L1 cells acquire resistance against oxidative stress as the adipocytes differentiate via the transcription factor FoxO," Apoptosis, vol. 15, no. 1, pp. 83-93, 2010, Springer US.

[65] X. Yang, C. J. Li, Y. Wan, P. Smith, G. Shang, and Q. Cui, "Antioxidative fullerol promotes osteogenesis of human adipose-derived stem cells," International Journal of Nanomedicine, vol. 9, pp. 4023-4031, 2014.

[66] Z. Wang, H. Li, R. Guo, Q. Wang, and D. Zhang, "Antioxidants inhibit advanced glycosylation end-product-induced apoptosis by downregulation of miR-223 in human adipose 
tissue-derived stem cells," Scientific Reports, vol. 6, pp. 1-11, 2016, Nature Publishing Group.

[67] J.-H. Chung, Y.-S. Kim, K. Noh, Y.-M. Lee, S.-W. Chang, and E.-C. Kim, "Deferoxamine promotes osteoblastic differentiation in human periodontal ligament cells via the nuclear factor erythroid 2-related factor-mediated antioxidant signaling pathway," Journal of Periodontal Research, vol. 49, no. 5, pp. 563-573, 2014.

[68] S. Philipp, L. Cui, B. Ludolph et al.J. M. Downey et al., "Desferoxamine and ethyl-3,4-dihydroxybenzoate protect myocardium by activating NOS and generating mitochondrial ROS," American Journal of Physiology-Heart and Circulatory Physiology, vol. 290, no. 1, p. H450, 2005.

[69] C.-N. Im, J.-S. Lee, Y. Zheng, and J.-S. Seo, "Iron chelation study in a normal human hepatocyte cell line suggests that tumor necrosis factor receptor-associated protein 1 (TRAP1) regulates production of reactive oxygen species," Journal of Cellular Biochemistry, vol. 100, no. 2, pp. 474-486, 2007, Wiley Subscription Services, Inc., A Wiley Company.

[70] E. Ardite, J. A. Barbera, J. Roca, and J. C. Fernández-Checa, "Glutathione depletion impairs myogenic differentiation of murine skeletal muscle $\mathrm{C} 2 \mathrm{C} 12$ cells through sustained NF- $\kappa \mathrm{B}$ activation," The American Journal of Pathology, vol. 165, no. 3, pp. 719-728, 2004.

[71] F. Esposito, V. Agosti, G. Morrone et al., "Inhibition of the differentiation of human myeloid cell lines by redox changes induced through glutathione depletion," Biochemical Journal, vol. 301, no. 3, pp. 649-653, 1994.

[72] L. Drowley, M. Okada, S. Beckman et al., "Cellular antioxidant levels influence muscle stem cell therapy," Molecular Therapy, vol. 18, no. 10, pp. 1865-1873, 2010, Nature Publishing Group.

[73] A. Paranjpe, N. A. Cacalano, W. R. Hume, and A. Jewett, "Nacetylcysteine protects dental pulp stromal cells from HEMAinduced apoptosis by inducing differentiation of the cells," Free Radical Biology and Medicine, vol. 43, no. 10, pp. 13941408, 2007.

[74] F. Aliakbari, M. A. S. Gilani, F. Amidi et al., "Improving the efficacy of cryopreservation of spermatogonia stem cells by antioxidant supplements," Cellular Reprogramming, vol. 18, no. 2, pp. 87-95, 2016, Mary Ann Liebert, Inc. 140 Huguenot Street, 3rd Floor New Rochelle, NY 10801 USA.

[75] M. Koruji, M. Koruji, M. Movahedin, S. J. Mowla, and H. Gourabi, "Colony formation ability of frozen thawed spermatogonial stem cell from adult mouse," International Journal of Reproductive BioMedicine, vol. 5, no. 3, pp. 109-115, 2012.

[76] T. Mirzapour, M. Movahedin, T. A. Tengku Ibrahim, A. W. Haron, and M. R. Nowroozi, "Evaluation of the effects of cryopreservation on viability, proliferation and colony formation of human spermatogonial stem cells in vitro culture," Andrologia, vol. 45, no. 1, pp. 26-34, 2013.

[77] Y. Ikeda, T. Yoshinari, H. Miyoshi, and Y. Nagasaki, "Design of antioxidative biointerface for separation of hematopoietic stem cells with high maintenance of undifferentiated phenotype," Journal of Biomedical Materials Research Part A, vol. 104, no. 8, pp. 2080-2085, 2016.

[78] T. Wang, G. Zeng, X. Li, and H. Zeng, "In vitro studies on the antioxidant and protective effect of 2-substituted-8-hydroxyquinoline derivatives against $\mathrm{H} 2 \mathrm{O} 2$-induced oxidative stress in BMSCs," Chemical Biology \& Drug Design, vol. 75, no. 2, pp. 214-222, 2010.

[79] N. K. Mekala, R. R. Baadhe, S. R. Parcha, and D. Y. Prameela, "Enhanced proliferation and osteogenic differentiation of human umbilical cord blood stem cells by L-ascorbic acid, in vitro," Current Stem Cell Research \& Therapy, vol. 8, no. 2, pp. 156-162, 2013.

[80] E. Ko, K. Y. Lee, and D. S. Hwang, "Human umbilical cord blood-derived mesenchymal stem cells undergo cellular senescence in response to oxidative stress," Syem Cells and Development, vol. 21, no. 11, pp. 1877-1886, 2012.

[81] W. Zeng, J. Xiao, G. Zheng, F. Xing, G. L. Tipoe, and X. Wang, "Antioxidant treatment enhances human mesenchymal stem cell anti-stress ability and therapeutic efficacy in an acute liver failure model," Scientific Reports, vol. 5, article 11100, 2015, Nature Publishing Group.

[82] T. Takahashi, B. Lord, P. C. Schulze et al., "Ascorbic acid enhances differentiation of embryonic stem cells into cardiac myocytes," Circulation, vol. 107, no. 14, pp. 1912-1917, 2003.

[83] J. Yu, T. Yuan-Kun, and N.-C. C. Yueh-Bih Tang, "Stemness and transdifferentiation of adipose- derived stem cells using L-ascorbic acid 2," Biomaterials, vol. 35, no. 11, pp. 35163526, 2014.

[84] M. W. El Husseny, M. Mamdouh, S. Shaban et al., "Adipokines: potential therapeutic targets for vascular dysfunction in type II diabetes mellitus and obesity," Journal of Diabetes Research, vol. 2017, Article ID 8095926, 11 pages, 2017. 


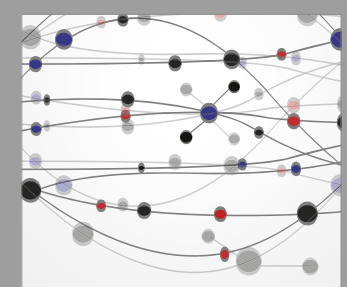

The Scientific World Journal
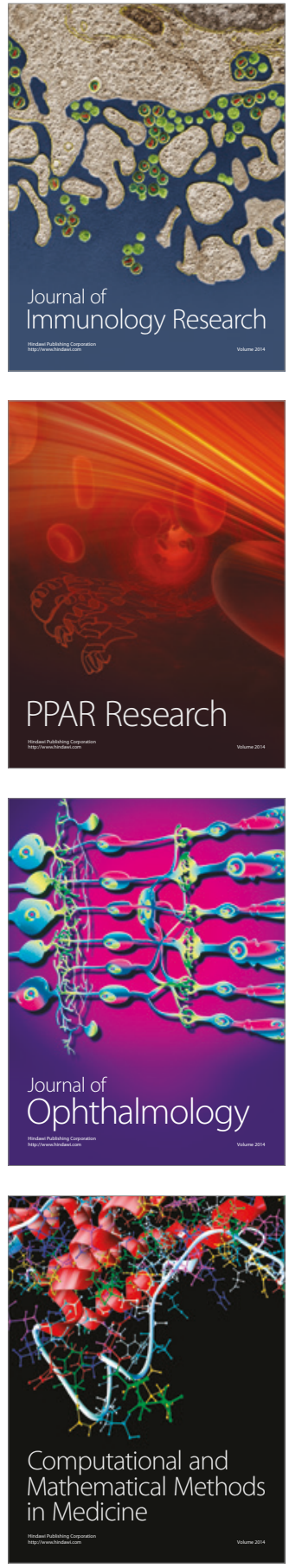

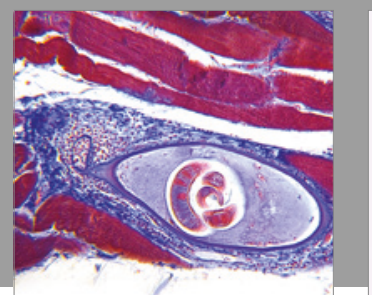

Gastroenterology Research and Practice
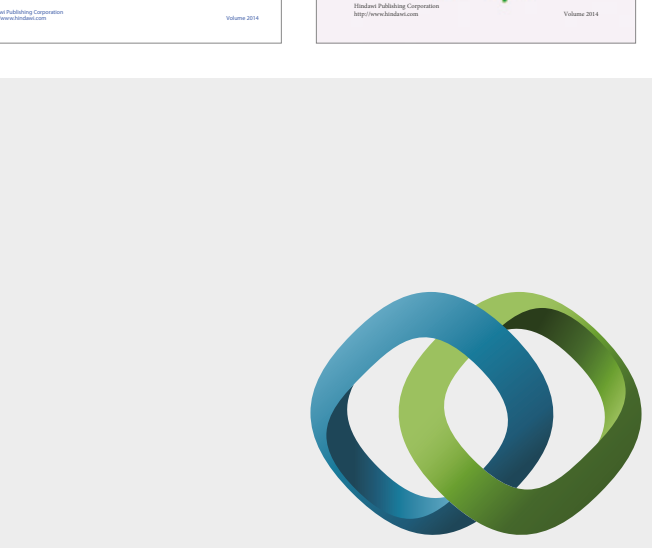

\section{Hindawi}

Submit your manuscripts at

https://www.hindawi.com
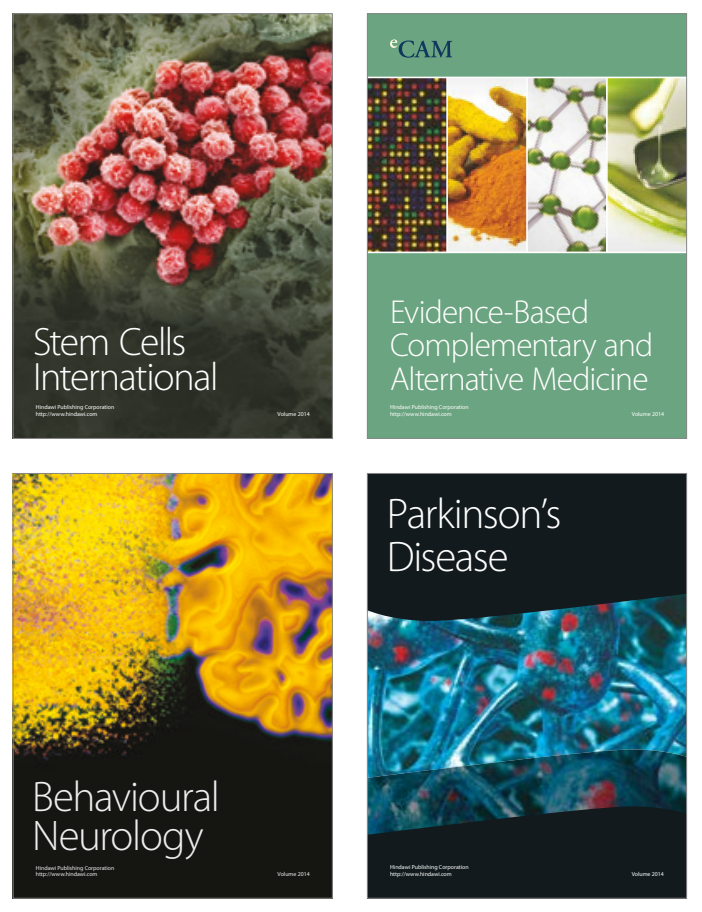
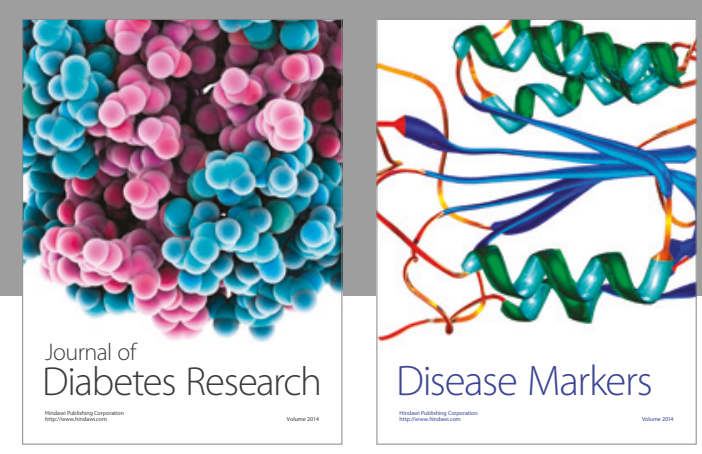

Disease Markers
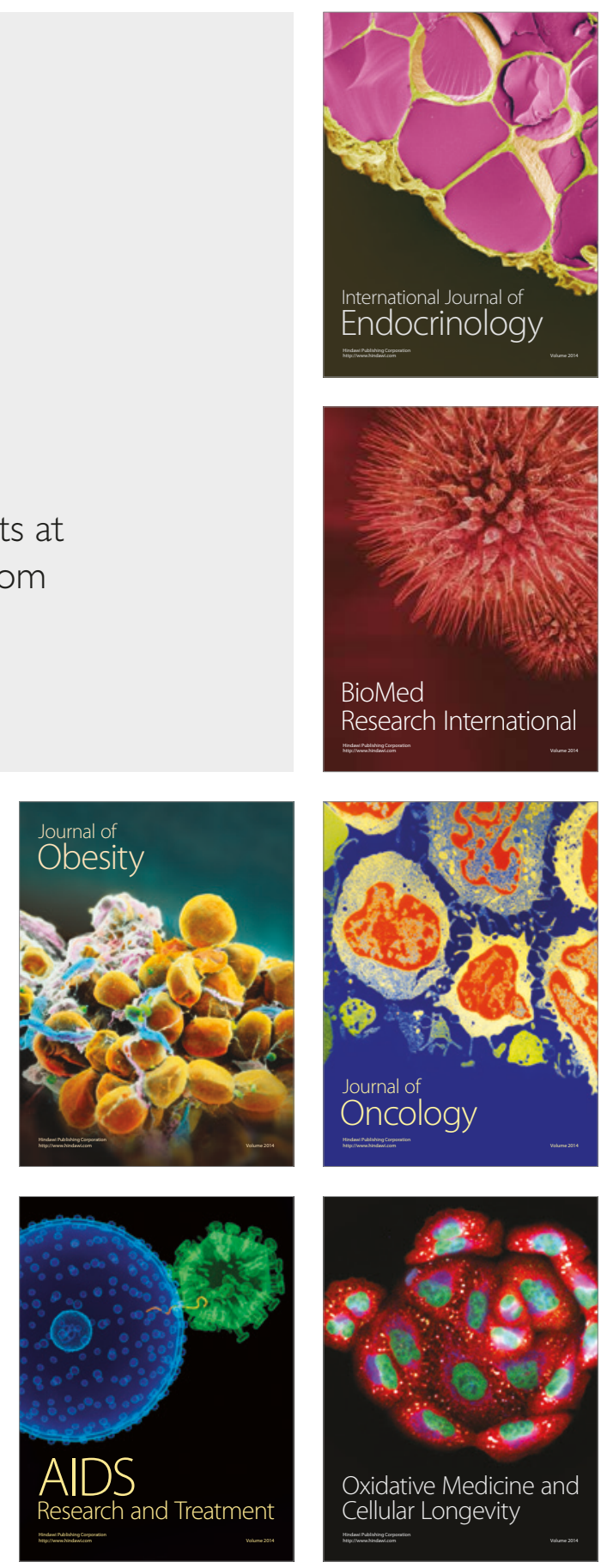